\title{
Extracts of six Rubiaceae species combined with rifampicin have good in vitro synergistic antimycobacterial activity and good anti-inflammatory and antioxidant activities
}

Abimbola O. Aro', Jean P. Dzoyem ${ }^{1,2^{*}}$, Jacobus N. Eloff ${ }^{1}$ and Lyndy J. McGaw ${ }^{1}$

\begin{abstract}
Background: The Rubiaceae family has played a significant role in drug discovery by providing molecules with potential use as templates for the development of therapeutic drugs. This study was designed to study the in vitro synergistic effect of six Rubiaceae species in combination with a known anti-TB drug. The antioxidant and anti-inflammatory activity of these species were also evaluated to investigate additional benefits in antimycobacterial treatment.

Methods: The checkerboard method was used to determine the antimycobacterial synergistic activity of plant extracts combined with rifampicin. The antioxidant activity of extracts was determined by the 2,2-diphenyl1-picrylhydrazyl (DPPH) method. Anti-inflammatory activity via inhibition of nitric oxide (NO) production was performed in LPS-activated RAW 264.7 macrophages using the Griess assay.

Results: Combination of rifampicin with the crude extracts resulted in a 4 to 256 -fold increase of activity of extracts. The crude extract of Cremaspora triflora produced the best synergistic effect with rifampicin, with a fractional inhibitory concentration (FIC) index of 0.08 against Mycobacterium aurum. Extracts of Psychotria zombamontana had the best antioxidant activity with an $\mathrm{IC}_{50}$ value of $1.77 \mu \mathrm{g} / \mathrm{mL}$, lower than the $\mathrm{IC}_{50}$ of trolox and ascorbic acid $(5.67 \mu \mathrm{g} / \mathrm{mL}$ and $4.66 \mu \mathrm{g} / \mathrm{mL}$ respectively). All the extracts tested inhibited nitric oxide (NO) production in a concentration dependent manner with the percentage of inhibition varying from 6.73 to $86.27 \%$.

Conclusion: Some of the Rubiaceae species investigated have substantial in vitro synergistic effects with rifampicin and also good free radical scavenging ability and anti-inflammatory activity. These preliminary results warrant further study on these plants to determine if compounds isolated from these species could lead to the development of bioactive compounds that can potentiate the activity of rifampicin even against resistant mycobacteria.
\end{abstract}

Keywords: Synergy, Antimycobacterial, Antioxidant, Nitric oxide, Rubiaceae, Tuberculosis

\footnotetext{
* Correspondence: jpdzoyem@yahoo.fr

'Phytomedicine Programme, Department of Paraclinical Sciences, Faculty of Veterinary Science, University of Pretoria, Private Bag X04, Onderstepoort 0110, South Africa

${ }^{2}$ Present Address: Department of Biochemistry, Faculty of Science, University of Dschang, P.O. Box 67, Dschang, Cameroon
} 


\section{Background}

The emergence of drug resistant tuberculosis (TB) strains (including multi drug resistant, MDR and extremely drug resistant, XDR) has reduced the efficacy of first-line anti-TB drugs. Therefore, there is an urgent need to design drugs that can act in synergy with previously potent anti-TB drugs. The implementation of combination therapy is of great importance for the treatment of infectious diseases, as monotherapy is often associated with an increase in the development of resistance. In order to improve the cure rate of infectious disease and curb the upsurge of resistance, combination therapy is encouraged, as has been shown with the multidrug approach used to treat tuberculosis (Isoniazid, Rifampicin, Pyrazinamide and Ethambutol). Without such combination therapy, the death rate of infected patients could have reached global epidemic proportions [1].

Most in vitro studies determine the therapeutic effect of new drugs as single agents, but in clinical practice to prevent the development of drug resistance, a combination of various drugs is imperative [2]. Combination studies with natural products from plants and synthetic drugs are limited to relatively few reports. Therefore, evaluating the in vitro effect of bioactive extracts or compounds with the classic anti-TB drugs is necessary and may lead to more effective treatment of TB $[3,4]$.

One of the manifestations of inflammation is oxidative stress, and the pathways that generate the mediators of inflammation are all induced by oxidative stress [5]. Most of the potentially harmful effects of oxygen are due to the formation of reactive oxygen species (ROS). The role played by the reactive oxygen intermediates during TB infection is not fully understood, but it is known that hydrogen peroxide produced by macrophages which have been activated by cytokines has mycobactericidal activity [6]. Excess reactive oxygen species (ROS) generated could however, lead to inflammation, and antioxidant substances that can scavenge and eliminate ROS may be useful in preventing or minimizing oxidation-related diseases such as TB [7]. Costantino et al. [8] reported several studies showing the correlation between antioxidant properties of plants with oxidative stress defence.

Nitric oxide (NO) plays a significant role during the host defence response against different pathological organisms such as bacteria, viruses, parasites and fungi [9]. $\mathrm{NO}$ is important in regulating diverse pathophysiological process in the body under normal physiological conditions [10]. It is a free radical involved in many biological processes, with the ability to enhance the bactericidal activity of activated macrophages [11]. In case of treatment failure or of infection with resistant strains, mycobacteria persist in the macrophages of the host for a long period. This can lead to an overexpression of inflammatory mediators including nitric oxide and further generate oxidative stress due to an imbalance between pro-oxidant and antioxidant systems. Furtermore, excessive production of NO may lead to potential tissue damage associated with acute and chronic inflammation [12]. Many researchers have demonstrated the potential of medicinal plant extracts to scavenge free radicals and modulate inflammatory reactions $[13,14]$. The mammalian immune system combats pathogens through activated macrophages, thereby providing microbicidal activity before the initiation of various pro-inflammatory mediators such as NO [10]., Lipopolysaccharide (LPS) a Gram-negative bacterial cell wall component is a good activator of macrophages, and is also involved in the production of pro-inflammatory cytokines [15]. Therefore, much attention is being given to the invention of drugs which can act as potent inhibitors of $\mathrm{NO}$ production (such as that detected in LPS stimulated RAW 264.7 cells) as a possible treatment for chronic inflammatory disease [16]. Plant products have been used in the development of new drugs, and they continue to play an important role in the discovery and development of new drugs [17]. Therefore, plant products that can inhibit the production of NO may be a potential therapy for those diseases in which inflammation plays a role [18].

Various species from the Rubiaceae family have proven to be a promising source of new bioactive substances which may lead to the development of new products as active molecules or drug prototypes due to their structural diversity and pharmacological activities [19]. One peculiar characteristic of this family is that they contain a wide range of secondary metabolites such as alkaloids, flavonoids, terpenes, anthraquinones and coumarins having good pharmacological properties [20]. These classes of secondary metabolites have been associated with antimicrobial, anti-malarial, hepatoprotective, antioxidant, and many other interesting biological activities [21].

In a previous study, six species from the Rubiaceae family, namely Cephalanthus natalensis, Cremaspora triflora, Oxyanthus speciosus, Pavetta lanceolata, Psychotria capensis and Psychotria zombamontana were shown to have good antimycobacterial activity [22]. These species were selected for further study to determine their synergistic activity with a known antimycobacterial drug., The antioxidant and nitric oxide inhibitory properties were also determined in an effort to gain more insight into their potential mechanism of action.

\section{Methods}

\section{Plant collection}

The leaves of plants were collected in the Pretoria National Botanical Garden in terms of a signed material 
transfer agreement. The plant materials were identified by the curator and labelled. Voucher specimens were kept in the HGWJ Schweickerdt Herbarium of the University of Pretoria (PRU) (Table 1). The leaves were air-dried at room temperature, ground to a fine powder in a Macsalab mill (Model 200 LAB, Eriez, Bramley, Johannesburg, South Africa) and stored in closed glass containers in the dark until needed. Acetone was selected as the extracting solvent for the dried leaf powder owing to its ability to extract a wide range of compounds and its low toxicity in the antimicrobial bioassay [23]. Ground leaf material was extracted by acetone in a ratio of 10:1 (v:m), evaporated to dryness and made up to a concentration of $10 \mathrm{mg} / \mathrm{mL}$.

\section{Mycobacterial culture}

Antimycobacterial activity was tested against two non-tuberculous mycobacteria (NTM): Mycobacterium smegmatis (ATCC 1441) and Mycobacterium aurum (NCTC 10437), as well as against a $M$. tuberculosis field strain (TB 8104) which was isolated from a waterbuck and genetically characterized using variable number of tandem repeat typing based on a 13-locus VNTR panel [24].

\section{In vitro synergistic antimycobacterial activity}

The effect of combinations of the acetone extracts of Cremaspora triflora, Cephalanthus natalensis, Oxyanthus speciosus, Pavetta lanceolata, Psychotria capensis and Psychotria zombamontana with rifampicin (RIF, Sigma) against three mycobacteria were determined using the checkerboard method [25]. Rifampicin was dissolved in DMSO (0.25 \%). The Fractional Inhibitory Concentration (FIC) of each drug was calculated by dividing the concentration of the extract present in that well in combination, where complete inhibition of growth of the microorganism was observed, by the MIC of that extract alone to inhibit the microorganism. All assays were performed in triplicate. The $\Sigma F I C$ was then calculated for each test sample independently as specified in the following equations:

FIC (a) = MIC (a) in combination with (b)/ MIC (a) alone

FIC (b) = MIC (b) in combination with (a)/ MIC (b) alone

The sum of the FIC or FIC index is thus calculated as: $\Sigma$ FIC $=$ FIC (a) + FIC (b)

The interpretations of the $\Sigma$ FICs were as follows: $\Sigma$ FIC $\leq$ $0.5=$ synergistic $; \quad>0.5-1.0=$ additive $; \quad>1.0-\leq 4.00=$ non interactive and $>4.0=$ antagonistic [1].

\section{DPPH assay}

The DPPH radical-scavenging activity was determined as previously described [7]. Ascorbic acid and trolox were used as positive controls, methanol as negative control and extract without DPPH as blank. Results were expressed as percentage reduction of the initial DPPH absorption in relation to the control. The concentration of extract leading to $50 \%$ reduction of $\mathrm{DPPH}\left(\mathrm{IC}_{50}\right)$ was also determined.

\section{Inhibition of nitric oxide (NO) production}

The NO production inhibitory activity of plant extracts was evaluated in the LPS-activated mouse macrophage cell line RAW 264.7 as previously described [7]. Validity of the assays was shown by using untreated cells as negative control, LPS-stimulated cells as positive control and additionally a cell group as reduction control group with LPS-stimulated cells, co-incubated together with quercetin used as an inhibitor of NO.

\section{Statistical analysis}

All experiments were conducted in triplicate and values expressed as mean \pm standard deviation. Statistical analysis was performed using one way ANOVA and results were compared using the Fisher's least significant difference (LSD) at a $5 \%$ significance level.

\section{Results}

The results of the combination of the six crude extracts with rifampicin against $M$. smegmatis, $M$. aurum and $M$. tuberculosis (8104) showed varying degrees of synergistic to non-interactive antimycobacterial effects. Upon addition of sub-minimal inhibitory concentrations of the acetone crude extracts to rifampicin, reduction of the MICs of the anti-TB drug ranged from 2-fold to 4-fold $(\Sigma F I C=0.5-1), 2$-fold to 64-fold $(\Sigma F I C=0.08-2)$ and 2fold to 64-fold ( $\Sigma F I C=0.19-1$ ) for M. smegmatis, $M$. aurum and $M$. tuberculosis respectively (Table 1). The MIC values of the crude extracts against the three tested mycobacteria were reduced to varying degrees. Cremaspora triflora and Pavetta lanceolata extract MIC values were decreased 16 -fold to 256 -fold in combination with rifampicin $(\Sigma F I C=0.08-0.5)$ against $M$. aurum. The crude extract of Pavetta lanceolata also showed some synergistic to additive effect.

Regarding antioxidant activity, plant extracts with $\mathrm{IC}_{50}<50 \mu \mathrm{g} / \mathrm{mL}$ are considered to have significant antioxidant activity while samples with $\mathrm{IC}_{50}>50 \mu \mathrm{g} / \mathrm{mL}$ are classified as having moderate antioxidant activity [26]. Compounds with $\mathrm{IC}_{50}<10 \mu \mathrm{g} / \mathrm{mL}$ are considered to have significant antioxidant capacity while $10<\mathrm{IC}_{50}<$ $20 \mu \mathrm{g} / \mathrm{mL}$ are considered moderate and $\mathrm{IC}_{50}>20 \mu \mathrm{g} / \mathrm{mL}$ are said to possess low antioxidant activity [27]. The lower the $\mathrm{IC}_{50}$ value of an extract, the higher its antioxidant activity. The crude extract of Psychotria zombamontana had the best antioxidant activity among the six tested extracts with an $\mathrm{IC}_{50}$ value of $1.77 \mu \mathrm{g} / \mathrm{mL}$ 
Table 1 Synergistic activity of extracts from six Rubiaceae species and rifampicin against Mycobacterium species

\begin{tabular}{|c|c|c|c|c|c|c|}
\hline \multirow[t]{2}{*}{ Extract/rifampicin } & \multirow{2}{*}{$\begin{array}{l}\text { Mycobacterial } \\
\text { strains }\end{array}$} & \multicolumn{2}{|l|}{ MIC $(\mu \mathrm{g} / \mathrm{ml})$} & \multicolumn{2}{|l|}{$\mathrm{FIC}^{\mathrm{a}}$} & \multirow[t]{2}{*}{ Interpretation } \\
\hline & & |ndividual $^{b}$ & Combination $^{c}$ & Individual & Index & \\
\hline \multirow[t]{9}{*}{ Cephalanthus natalensis/rifampicin } & \multirow[t]{3}{*}{ M. smegmatis } & \multirow[t]{3}{*}{$17 / 16$} & $0.531 / 8$ & $0.03 / 0.5$ & 0.53 & Synergy \\
\hline & & & $0.133 / 8$ & $0.008 / 0.5$ & 0.51 & Synergy \\
\hline & & & $0.066 / 8$ & $0.004 / 0.5$ & 0.5 & Synergy \\
\hline & \multirow[t]{3}{*}{ M. aurum } & \multirow[t]{3}{*}{$100 / 78$} & $50 / 1.21$ & $0.5 / 0.02$ & 0.52 & Synergy \\
\hline & & & $50 / 9.75$ & $0.5 / 0.13$ & 0.63 & Additive \\
\hline & & & $1.56 / 19.5$ & $0.02 / 0.25$ & 0.27 & Synergy \\
\hline & \multirow[t]{3}{*}{ M. tuberculosis } & \multirow[t]{3}{*}{$40 / 9$} & $40 / 1.125$ & $1 / 0.125$ & 1.125 & Non-interactive \\
\hline & & & $5 / 2.25$ & $0.125 / 0.25$ & 0.38 & Synergy \\
\hline & & & $2.5 / 2.25$ & $0.063 / 0.25$ & 0.31 & Synergy \\
\hline \multirow[t]{9}{*}{ Cremaspora triflora/rifampicin } & \multirow[t]{3}{*}{ M. smegmatis } & \multirow[t]{3}{*}{$23 / 16$} & $11.5 / 8$ & $0.5 / 0.5$ & 1 & Additive \\
\hline & & & $5.7 / 8$ & $0.25 / 0.5$ & 0.75 & Additive \\
\hline & & & $2.88 / 8$ & $0.125 / 0.5$ & 0.63 & Additive \\
\hline & \multirow[t]{3}{*}{ M. aurum } & \multirow[t]{3}{*}{$100 / 78$} & $6.25 / 1.21$ & $0.063 / 0.016$ & 0.08 & Synergy \\
\hline & & & $50 / 2.43$ & $0.5 / 0.031$ & 0.53 & Synergy \\
\hline & & & $25 / 4.87$ & $0.25 / 0.063$ & 0.31 & Synergy \\
\hline & \multirow[t]{3}{*}{ M. tuberculosis } & \multirow[t]{3}{*}{$160 / 9$} & $40 / 0.14$ & $0.25 / 0.016$ & 0.27 & Synergy \\
\hline & & & $20 / 0.56$ & $0.125 / 0.062$ & 0.19 & Synergy \\
\hline & & & $10 / 1.125$ & $0.062 / 0.125$ & 0.19 & Synergy \\
\hline \multirow[t]{9}{*}{ Oxyanthus speciosus/rifampicin } & \multirow[t]{3}{*}{ M. smegmatis } & \multirow[t]{3}{*}{$80 / 16$} & 20/8 & $0.25 / 0.5$ & 0.75 & Additive \\
\hline & & & $10 / 8$ & $0.125 / 0.5$ & 0.63 & Additive \\
\hline & & & $5 / 8$ & $0.06 / 0.5$ & 0.56 & Additive \\
\hline & \multirow[t]{3}{*}{ M. aurum } & \multirow[t]{3}{*}{$60 / 78$} & $60 / 78$ & $1 / 1$ & 2 & Non-interactive \\
\hline & & & $30 / 78$ & $0.5 / 1$ & 1.5 & Non-interactive \\
\hline & & & $15 / 78$ & $0.25 / 1$ & 1.25 & Non-interactive \\
\hline & M. tuberculosis & $170 / 9$ & $85 / 2.25$ & $0.5 / 0.25$ & 0.75 & Additive \\
\hline & & & $21.25 / 2.25$ & $0.125 / 0.25$ & 0.38 & Synergy \\
\hline & & & $5.31 / 2.25$ & $0.031 / 0.25$ & 0.28 & Synergy \\
\hline Pavetta lanceolata/rifampicin & M. smegmatis & $12 / 16$ & $6 / 8$ & $0.5 / 0.5$ & 1 & Additive \\
\hline & & & $3 / 8$ & $0.25 / 0.5$ & 0.75 & Additive \\
\hline & & & $1.5 / 8$ & $0.125 / 0.5$ & 0.63 & Additive \\
\hline & M. aurum & 100/78 & $6.25 / 39$ & $0.063 / 0.5$ & 0.56 & Additive \\
\hline & & & $0.781 / 39$ & $0.008 / 0.5$ & 0.51 & Synergy \\
\hline & & & $0.391 / 39$ & $0.004 / 0.5$ & 0.5 & Synergy \\
\hline & M. tuberculosis & $120 / 9$ & $60 / 2.25$ & $0.5 / 0.25$ & 0.75 & Additive \\
\hline & & & $30 / 4.5$ & $0.25 / 0.5$ & 0.75 & Additive \\
\hline & & & $7.5 / 4.5$ & $0.063 / .05$ & 0.56 & Additive \\
\hline Psychotria capensis/rifampicin & M. smegmatis & $60 / 16$ & $30 / 8$ & $0.5 / 0.5$ & 1 & Additive \\
\hline & & & $15 / 8$ & $0.25 / 0.5$ & 0.75 & Additive \\
\hline & & & $7.5 / 8$ & $0.125 / 0.5$ & 0.63 & Additive \\
\hline & M. aurum & $120 / 78$ & $30 / 19.5$ & $0.25 / 0.25$ & 0.5 & Synergy \\
\hline & & & $15 / 39$ & $0.13 / 0.5$ & 0.63 & Additive \\
\hline & & & $3.75 / 39$ & $0.03 / 0.5$ & 0.53 & Synergy \\
\hline
\end{tabular}


Table 1 Synergistic activity of extracts from six Rubiaceae species and rifampicin against Mycobacterium species (Continued)

\begin{tabular}{|c|c|c|c|c|c|c|}
\hline & M. tuberculosis & $630 / 9$ & $315 / 4.5$ & $0.5 / 0.5$ & 1 & Additive \\
\hline & & & $157.5 / 4.5$ & $0.25 / 0.5$ & 0.75 & Additive \\
\hline & & & $78.75 / 4.5$ & $0.125 / 0.5$ & 0.63 & Additive \\
\hline \multirow[t]{9}{*}{ Psychotria zombamontana/rifampicin } & M. smegmatis & $40 / 16$ & $10 / 8$ & $0.25 / 0.5$ & 0.75 & Additive \\
\hline & & & $5 / 8$ & $0.125 / 0.5$ & 0.63 & Additive \\
\hline & & & $2.5 / 8$ & $0.06 / 0.5$ & 0.56 & Additive \\
\hline & M. aurum & $80 / 78$ & 20/19.5 & $0.25 / 0.25$ & 0.5 & Synergy \\
\hline & & & $10 / 19.5$ & $0.125 / 0.25$ & 0.38 & Synergy \\
\hline & & & $5 / 19.5$ & $0.063 / 0.25$ & 0.31 & Synergy \\
\hline & M. tuberculosis & $160 / 9$ & $80 / 2.25$ & $0.5 / 0.25$ & 0.75 & Additive \\
\hline & & & $40 / 2.25$ & $0.25 / 0.25$ & 0.5 & Synergy \\
\hline & & & $20 / 2.25$ & $0.125 / 0.25$ & 0.38 & Synergy \\
\hline
\end{tabular}

${ }^{a}$ FIC fractional inhibitory concentration for individual sample FIC index + = FIC (a) + FIC (b). ${ }^{b}$ MIC minimum inhibitory concentration for individual sample; ${ }^{\mathrm{c}} \mathrm{MIC}$ of samples in combination

compared to trolox and ascorbic acid (with $\mathrm{IC}_{50}$ values of $5.67 \mu \mathrm{g} / \mathrm{mL}$ and $4.66 \mu \mathrm{g} / \mathrm{mL}$ respectively). Based on the above cut-off criteria, Psychotria capensis also had good antioxidant activity with an $\mathrm{IC}_{50}$ value of $29.73 \mu \mathrm{g} / \mathrm{mL}$ while other extracts had moderate to weak antioxidant capacity $\left(\mathrm{IC}_{50}\right.$ values ranging from 68.64-259.7 $\mu \mathrm{g} / \mathrm{mL}$ ).

As shown in Table 2, all the extracts had a dose dependent inhibition of $\mathrm{NO}$ production at concentrations of $6.25,12.5,25$ and $50 \mathrm{mg} / \mathrm{mL}$. The crude acetone extract of Psychotria capensis had the best inhibitory activity on NO production ( $86.27 \%)$, but this is most likely due to cytotoxic effects of the extract on the RAW 264.7 macrophage cell line. Percentage cell viability at 50 and $25 \mu \mathrm{g} / \mathrm{mL}$ respectively was as low as $4.44 \%$ and $28.31 \%$. The acetone extract of Psychotria capensis has been reported for its cytotoxic effect on C3A human liver and Vero kidney cells [22]. Pavetta lanceolata also had good anti-inflammatory activity by inhibiting the production of NO by $70 \%$ with no concomitant cytotoxic effect on RAW 264.7 macrophages.

\section{Discussion}

Spontaneous genetic mutations in Mycobacterium tuberculosis may lead to the emergence of drug resistant strains following inconsistent or inappropriate single drug therapy using selected anti-TB drugs [28]. Rifampicin is one of the most effective first-line TB drugs which is active against drug-susceptible $\mathrm{TB}$, but the emergence of resistant strains is threatening the continued efficacy of this drug. Synergistic effects can occur if the constituents of an extract affect different targets or interact with one another in order to enhance the bioavailability of one or several substances of an extract [29]. The acetone extract of Cremaspora triflora in combination with rifampicin had the best fractional inhibitory concentration $(\Sigma F I C=0.08)$ showing a synergistic effect and leading to a 64-fold reduction in the MIC of rifampicin i.e. a 64-fold increase in the antimycobacterial activity. Oxyanthus speciosus in combination with rifampicin had a non-interactive effect $(\Sigma F I C=2)$ against $M$. aurum. Based on this assay, only a two-fold reduction in the MIC of rifampicin was observed against $M$. smegmatis. Encouragingly, no antagonist effect was observed using the different combinations against all the tested strains. Synergy in terms of natural product combinations may be affected by many factors such as: pharmacokinetics, physicochemical properties, complex multi-target effects or therapeutic approaches [29].

It has been reported that the antioxidant activity of plant materials is well correlated with the content of their phenolic compounds [30]. Different studies have also shown a positive correlation between phenolic compounds and terpene concentration with antimicrobial activity [31, 32].

Of the six extracts tested, Psychotria zombamonatana and Psychotria capensis had good antioxidant activity. Others had only moderate to weak free radical scavenging capacity, with Oxyanthus speciosus having the lowest antioxidant activity. Extracts with good inhibitory activity on NO production and low cytotoxicity are more useful for potential therapeutic application. Antiinflammatory activity of plant extracts above $70 \%$ at a concentration of $250 \mu \mathrm{g} / \mathrm{ml}$ is considered significant [33]. The six crude extracts screened in this study all led to dose-dependent NO inhibition. However, when compared with the activity of quercetin, the extracts did not meaningfully inhibit the production of NO, except for the acetone extract of Psychotria capensis. This extract had toxicity to the LPS-stimulated RAW 264.7 macrophage cell line, which limits its usefulness. The synergistic effect of many compounds in natural products 
Table 2 Antioxidant and NO production inhibitory activity and cell viability of extracts from six Rubiaceae species

\begin{tabular}{|c|c|c|c|c|c|c|}
\hline Samples & Concentration $(\mu \mathrm{g} / \mathrm{mL})$ & $\mathrm{NO}(\mu \mathrm{M})$ & $\%$ NO inhibition & Cell viability & $\mathrm{DPPH}\left(\mathrm{IC}_{50}\right.$ in $\left.\mu \mathrm{g} / \mathrm{mL}\right)$ & Voucher no \\
\hline \multirow[t]{4}{*}{ Cephalanthus natalensis } & 50 & $1.26 \pm 0.14$ & 53.81 & 104.67 & \multirow[t]{4}{*}{$68.64 \pm 0.20^{\mathrm{a}}$} & \multirow[t]{4}{*}{ PRU 120872} \\
\hline & 25 & $1.32 \pm 0.09$ & 51.39 & 100.84 & & \\
\hline & 12.5 & $1.80 \pm 0.08$ & 33.95 & 90.02 & & \\
\hline & 6.25 & $2.34 \pm 0.06$ & 14.10 & 76.19 & & \\
\hline \multirow[t]{4}{*}{ Cremaspora triflora } & 50 & $1.97 \pm 0.16$ & 27.66 & 96.70 & \multirow[t]{4}{*}{$90.02 \pm 0.10^{b}$} & \multirow[t]{4}{*}{114710} \\
\hline & 25 & $2.43 \pm 0.13$ & 10.70 & 105.20 & & \\
\hline & 12.5 & $2.48 \pm 0.08$ & 8.77 & 104.25 & & \\
\hline & 6.25 & $2.90 \pm 0.06$ & 6.73 & 118.31 & & \\
\hline \multirow[t]{4}{*}{ Oxyanthus speciosus } & 50 & $1.63 \pm 0.06$ & 40.25 & 109.84 & \multirow[t]{4}{*}{$259.7 \pm 0.23^{c}$} & \multirow[t]{4}{*}{ PRU 120873} \\
\hline & 25 & $1.57 \pm 0.07$ & 42.19 & 97.04 & & \\
\hline & 12.5 & $1.77 \pm 0.12$ & 34.92 & 91.61 & & \\
\hline & 6.25 & $1.94 \pm 0.15$ & 28.63 & 88.82 & & \\
\hline \multirow[t]{4}{*}{ Pavetta lanceolata } & 50 & $0.80 \pm 0.16$ & 70.77 & 101.73 & \multirow[t]{4}{*}{$138.94 \pm 0.18^{d}$} & \multirow[t]{4}{*}{ PRU 120874} \\
\hline & 25 & $1.26 \pm 0.10$ & 53.81 & 112.10 & & \\
\hline & 12.5 & $1.84 \pm 0.13$ & 32.50 & 116.49 & & \\
\hline & 6.25 & $2.52 \pm 0.10$ & 7.31 & 123.03 & & \\
\hline \multirow[t]{4}{*}{ Psychotria capensis } & 50 & $0.37 \pm 0.05$ & 86.27 & 4.44 & \multirow[t]{4}{*}{$29.73 \pm 0.22^{e}$} & \multirow[t]{4}{*}{ PRU 120875} \\
\hline & 25 & $1.08 \pm 0.77$ & 60.11 & 28.31 & & \\
\hline & 12.5 & $2.97 \pm 0.22$ & 9.16 & 75.40 & & \\
\hline & 6.25 & $3.22 \pm 0.23$ & 18.36 & 115.71 & & \\
\hline \multirow[t]{4}{*}{ Psychotria zombamontana } & 50 & $2.19 \pm 0.10$ & 19.42 & 114.53 & \multirow[t]{4}{*}{$1.77 \pm 0.13^{f}$} & \multirow[t]{4}{*}{ PRU 120867} \\
\hline & 25 & $2.02 \pm 0.20$ & 25.72 & 93.32 & & \\
\hline & 12.5 & $2.05 \pm 0.14$ & 24.75 & 91.92 & & \\
\hline & 6.25 & $2.40 \pm 0.10$ & 11.67 & 76.91 & & \\
\hline \multirow[t]{4}{*}{ Quercetin } & 25 & $0.35 \pm 0.10$ & 95.54 & 49.33 & \multirow[t]{4}{*}{ nd } & \\
\hline & 12.5 & $0.30 \pm 0.05$ & 96.14 & 60.69 & & \\
\hline & 6.25 & $0.69 \pm 0.08$ & 91.08 & 73.76 & & \\
\hline & 3.12 & $2.50 \pm 0.48$ & 73.76 & 73.10 & & \\
\hline Trolox & nd & nd & nd & nd & $5.67 \pm 0.24^{f}$ & nd \\
\hline Ascorbic acid & nd & nd & nd & nd & $4.66 \pm 0.25^{h}$ & nd \\
\hline
\end{tabular}

Values with different letters are significantly different at $p<0.05$

enhances their antioxidant properties. The acetone extract of Psychotria capensis showed a synergistic antimycobacterial effect in combination with rifampicin and also had good antioxidant activity while inhibiting the production of NO.

Antioxidants act by scavenging free radicals such as reactive oxygen species, hydroxyl radicals and nitric oxide while anti-inflammatory mediators act by modulating the activities of pro-inflammatory enzymes and cytokines. In inflammation, nitric oxide (NO) acts as a pro-inflammatory mediator and is synthesized by inducible nitric oxide synthase (iNOS) in response to proinflammatory agents such as lipopolysaccharide (LPS) [34]. The inhibitory activity of NO production by medicinal plants may originate from the inhibition of iNOS enzyme activity and/or expression of nitric oxide synthase [35]. Many natural compounds from medicinal plants are known inhibitors of iNOS expression in LPSactivated macrophages [36]. No report could be found on the inhibitory activity of the Rubiaceae plant extracts tested in this study on NO synthesis in LPS-activated RAW 264.7 cells. The selected plant species have been reported for their antimycobacterial activities against mycobacteria but possess weak antioxidant and antiinflammatory activity. Because of the role rifampicin plays in the treatment of $\mathrm{TB}$, researchers are interested in compounds that can display synergistic activity with this efficacious anti-TB drug in order to increase both therapeutic efficacy and reduce toxicity commonly observed by this drug $[37,38]$. 
Despite the weak antioxidant and anti-inflammatory activities, these plant extracts were able to decrease the MIC of rifampicin, thereby enhancing the mycobactericidal activity of this drug. The synergistic interaction observed in this study may be important, as rifampicin plays a pertinent role in reducing the duration of treatment for TB, thereby enhancing patients' compliance to prevent the development of drug resistant cases. Furthermore, reducing the dosage of rifampicin by using different drug combinations could reduce adverse effects observed during administration of this antimycobacterial drug.

\section{Conclusion}

This study investigated the in vitro synergistic activity of six Rubiaceae species in combination with the first-line antitubercular drug rifampicin. All the screened crude extracts produced synergistic to additive effects at different concentrations when combined with rifampicin but no antagonist effect was observed. A promising observation was the lack of cytotoxicity observed with some of the extracts. Whole animal studies are required to confirm the low toxicity of the extracts. The findings from this study are preliminary but are sufficient to warrant further study on these Rubiaceae species, as compounds isolated from these species could lead to the development of novel antimycobacterial compounds.

\section{Abbreviations \\ DPPH: 2,2-diphenyl-1-picrylhydrazyl; FIC: Fractional inhibitory concentration; iNOS: Inducible nitric oxide synthase; LPS: Lipopolysaccharide; MDR: Multi drug resistant; MIC: Minimum inhibitory concentration; NO: Nitric oxide; RIF: Rifampicin; ROS: Reactive oxygen species; TB: Tuberculosis; XDR: Extremely drug resistant}

\section{Acknowledgements}

The University of Pretoria Institutional Research Theme for Animal and Zoonotic Diseases (IRT-AZD), National Research Foundation (NRF, Grant No 81010) and Medical Research Council (MRC) of South Africa provided funding to support this study. The National Research Foundation

(NRF) provided a doctoral fellowship to AOA. The University of Pretoria provided a postdoctoral fellowship to JPD.

\section{Availability of data and materials}

Data supporting our findings are contained within the manuscript.

\section{Authors' contributions}

$\mathrm{AOA}$ and JPD performed experiments and wrote the first draft of manuscript. LJM and JNE supervised the work and revised the final manuscript. All authors read and approved the final manuscript.

\section{Competing interests}

The authors declare that they have no competing interests.

\section{Consent for publication}

Not applicable.

\section{Ethics approval and consent to participate}

Not applicable.

Received: 8 December 2015 Accepted: 9 September 2016 Published online: 03 October 2016

\section{References}

1. Van Vuuren S, Viljoen A. Plant-based antimicrobial studies - methods and approaches to study the interaction between natural products. Planta Med. 2011:77:1168-82.

2. Bergmann JS, Woods GL. In vitro activity of antimicrobial combinations against clinical isolates of susceptible and resistant Mycobacterium tuberculosis. Int J Tuberc Lung Dis. 1998;2(8):621-6.

3. Bapela NB, Lall N, Fourie PB, Franzblau SG, Van Rensburg CEJ. Activity of 7-methyljuglone in combination with antituberculous drugs against Mycobacterium tuberculosis. Phytomedicine. 2006;13(9-10):630-5.

4. Dye C. Doomsday postponed? Preventing and reversing epidemics of drug-resistant tuberculosis. Nat Rev Microbiol. 2009;7:81-7.

5. Sommer C. Inflammation and healing. In: Mattson CP, editor. Pathophysiology. seventhth ed. London: Lippincott Williams \& Wilkins; 2005. p. 387-98.

6. Reljic R, Stylianou E, Balu S, Ma JK. Cytokine interactions that determine the outcome of mycobacterial infection of macrophages. Cytokine. 2010;51:42-6.

7. Dzoyem JP, Eloff JN. Anti-inflammatory, anticholinesterase and antioxidant activity of leaf extracts of twelve plants used traditionally to alleviate pain and inflammation in South Africa. J Ethnopharmacol. 2015;160:194-201.

8. Costantino L, Albasini A, Rastelli G, Benvenuti S. Activity of polyphenolic crude extracts as scavengers of superoxide radicals and inhibitors of xanthine oxidase. Planta Med. 1992;58:342-4.

9. Bogdan C, Rollinghoff M, Diefenbach A. The role of nitric oxide in innate immunity. Immunol Rev. 2000;173:17-26.

10. Moncada S, Palmer RM, Higgs EA. Nitric oxide: physiology, pathophysiology, and pharmacology. Pharmacol Rev. 1991;43:109-42.

11. Nathan CF, Hibbs Jr JB. Role of nitric oxide synthesis in macrophage antimicrobial activity. Curr Opin Immunol. 1991;3:65-78.

12. Taira J, Nanbu H, Ueda K. Nitric oxide-scavenging compounds in Agrimonia pilosa Ledeb on LPS-induced RAW264.7 macrophages. Food Chem. 2009; 115:1221-7.

13. Lee MH, Lee JM, Jun SH, Lee SH, Kim NW, Lee JH, et al. The antiinflammatory effects of Pyrolae herba extract through the inhibition of the expression of inducible nitric oxide synthase (iNOS) and NO production. J Ethnopharmacol. 2007;112:49-54

14. Lee CJ, Chen LG, Liang WL, Wanga CC. Anti-inflammatory effects of Punica granatum Linne in vitro and in vivo. Food Chem. 2010;118:315-22.

15. Nicholas C, Batra S, Vargo MA, Voss OH, Gavrilin MA, Wewers MD, Guttridge DC, Grotewold E, Doseff Al. Apigenin blocks lipopolysaccharide-induced lethality in vivo and proinflammatory cytokines expression by inactivating NF-kappaB through the suppression of p65 phosphorylation. J Immunol. 2007;179:7121-7.

16. Pacher P, Beckman JS, Liaudet L. Nitric oxide and peroxynitrite in health and disease. Physiol Rev. 2007;87:315-424.

17. Raza M, Shaheen F, Choudhary MI, Suria A, Rahman UA, Sompong S, Delorenzo RJ. Anticonvulsant activities of the FS-1 subfraction isolated from roots of Delphinium denudatum. Phytother Res. 2001;15:426-30.

18. Nowakowska Z. A review of anti-infective and anti-inflammatory chalcones. Eur J Med Chem. 2007:42:125-37.

19. Martins $D$, Nunez CV. Secondary metabolites from Rubiaceae species. Molecules. 2015;20(7):13422-95.

20. Heitzman ME, Neto CC, Winiarz E, Vaisberg AJ, Hammond GB. "Ethnobotany, phytochemistry and pharmacology of Uncaria (Rubiaceae),". Phytochemistry. 2005;66(1):5-29.

21. Martins D, Carrion LL, Ramos DF, Salome KS, da Silva Almeida PE, Barison A, Nunez CV. Triterpenes and the antimycobacterial activity of Duroia macrophylla Huber (Rubiaceae). BioMed Res Int. 2013;2013:605831.

22. Aro AO, Dzoyem JP, Hlokwe TM, Madoroba E, Eloff JN, McGaw L. Some South African Rubiaceae tree leaf extracts have antimycobacterial activity against pathogenic and non-pathogenic Mycobacterium species. Phytother Res. 2015:29:1004-10.

23. Eloff JN. Which extractant should be used for screening and isolation of antimicrobial components from plants? J Ethnopharmacol. 1998:60:1-8.

24. Hlokwe TM, van Helden P, Michel A. Evaluation of the discriminatory power of variable number of tandem repeat typing of Mycobacterium bovis isolates from southern Africa. Transbound Emerg Dis. 2013;60:111-20.

25. Schelz Z, Molnar J, Hohmann J. Antimicrobial and antiplasmid activities of essential oils. Fitoterapia. 2006;77:279-85. 
26. Omisore NOA, Adewunmi CO, Iwalewa EO, Ngadjui BT, Adenowo TK, Abegaz BM, Ojewole JA, Watchueng J. Antitrichomonal and antioxi- dant activities of Dorstenia barteri and Dorstenia convexa. Braz J Med Biol Res. 2005;38:1087-94.

27. Kuete V, Efferth T. Cameroonian medicinal plants: pharmacology and derived natural products. Front Pharmacol. 2010;1:1-19.

28. Mitchison DA. How drug resistance emerges as a result of poor compliance during short course chemotherapy for tuberculosis. Int I Tuberc Lung Dis. 1998:2:10-5.

29. Wagner $\mathrm{H}$, Ulrich-merzenich G. Synergy research : approaching a new generation of Phytopharmaceuticals. Phytomedicine. 2009;16:97-110.

30. Velioglu YS, Mazza G, Gao L, Oomah BD. Antioxidant activity and total phenolics in selected fruits, vegetables, and grain products. J Agric Food Chem. 1998;46:4113-7.

31. Salomão K, Pereira PR, Campos LC, Borba CM, Cabello PH, Marcucci MC de Castro SL. Brazilian propolis: correlation between chemical composition and antimicrobial activity. Evid Based Complement Alternat Med. 2008;5(3):317-24.

32. Cushnie TP, Lamb AJ. Recent advances in understanding the antibacterial properties of flavonoids. Int J Antimicrob Agents. 2011;38(2):99-107.

33. Chinsamy M, Finnie JF, Van Staden J. Anti-inflammatory, antioxidant, anticholinesterase activity and mutagenicity of South African medicinal orchids. S Afr J Bot. 2014:91:88-98.

34. Lu YC, Yeh WC, Ohashi PS. LPS/TLR4 signal transduction pathway. Cytokine. 2008:42:145-51.

35. Ryu JH, Ahn H, Kim JY, Kim YK. Inhibitory activity of plant extracts on nitric oxide synthesis in LPS-activated macrophages. Phytother Res. 2003;17:485-9.

36. Son HJ, Lee HJ, Yun-Choi HS, Ryu JH. Inhibitors of nitric oxide synthesis and TNF-a expression from Magnolia obovata in activated macrophages. Planta Med. 2000;66:469-71.

37. Ge F, Zeng F, Liu S, Guo N, Ye H, Song Y, et al. In vitro synergistic activity between 8-methoxypsoralen and ethambutol, isoniazid, and rifampin when used in combination against Mycobacterium tuberculosis. World J Microbiol Biotechnol. 2010;26(4):623-8.

38. Lopes MA, Ferracioli KRC, Siqueira VLD, de Lima Scodro RB, Cortez DAG, da Silva RZ, Cardoso RF. In vitro interaction of eupomatenoid-5 from Piper solmsianum C. DC. var. solmsianum and anti-tuberculosis drugs. Int J Tuberc Lung Dis. 2014;18(12):1513-5.

\section{Submit your next manuscript to BioMed Central and we will help you at every step:}

- We accept pre-submission inquiries

- Our selector tool helps you to find the most relevant journal

- We provide round the clock customer support

- Convenient online submission

- Thorough peer review

- Inclusion in PubMed and all major indexing services

- Maximum visibility for your research

Submit your manuscript at www.biomedcentral.com/submit

) Biomed Central 